\title{
Possible germ cell-Sertoli cell interactions are critical for establishing appropriate expression levels for the Sertoli cell-specific MicroRNA, miR-202-5p, in human testis
}

Ali A Dabaja ${ }^{1}$, Anna Mielnik ${ }^{1}$, Brian D Robinson ${ }^{1,2}$, Matthew S Wosnitzer ${ }^{1}$, Peter N Schlegel ${ }^{1}$ and Darius A Paduch ${ }^{1 *}$

\begin{abstract}
Background: To examine human microRNA expression in fertile men and subsequently to compare expression patterns of miRNAs in fertile and infertile men, specifically men with Sertoli Cell Only (SCO) histopathology.

Methods: Testicular tissues from men with azoospermia and SCO, as well as those of men with normal spermatogenesis, were analyzed. MicroRNA was isolated using the miRCURYTM RNA Purification Kit. A miRCURY LNA ${ }^{\text {TM }}$ Universal RT system was used for detection of microRNA by quantitative real-time PCR. MicroRNA localization was performed by in situ hybridizations (ISH) on formalin-fixed paraffin embedded (FFPE) tissue utilizing miRCURY LNA ${ }^{\text {TM }}$ microRNA ISH technology. Statistical analysis was performed by GenEx V5.0.

Results: MicroRNA expression was determined for 13 normal fertile men and 5 men with the confirmed diagnosis of diffuse SCO. MiR-202-5p expression was reduced by 17 -fold $(P<0.00001)$ in tissue from SCO men compared to normal. MiR-34c-5p was reduced by 346-fold $(P<0.00001)$, miR-10b was reduced 18 -fold $(P<0.00001)$, miR-191 was reduced 20 -fold $(P=0.001)$ and miR-126 was reduced 40 -fold $(P<0.00001))$ in tissues from SCO compared to normal fertile men. Using ISH, miR-202-5p was localized to Sertoli cells of men with normal spermatogenesis, but not in the Sertoli cells of men with SCO.

Conclusion: Number of miRNAs are differentially expressed in normal fertile men compared to men with SCO. MicroRNA-202-5p is localized to Sertoli cells and its expression dramatically differs between fertile men and men whose germ cells are depleted, suggesting a novel interaction for regulating microRNA expression between the somatic and germ cell components of the seminiferous epithelium.
\end{abstract}

Keywords: MicroRNA, Spermatogenesis, Male infertility, miR-202-5p, Sertoli cells

\footnotetext{
*Correspondence: dap2013@med.cornell.edu

${ }^{1}$ Department of Reproductive Medicine, Weill Cornell Medical College, 525 East 68th St Starr 900, New York, NY 10065, USA

Full list of author information is available at the end of the article
} 


\begin{abstract}
Objectifs: Evaluer l'expression des microARN chez des hommes féconds puis comparer les profils d'expression de ces miRNAs chez des hommes féconds et des inféconds qui présentent plus particulièrement un syndrome de Sertoli seules (SCO) à l'histologie testiculaire.

Matériel et Méthodes: Ont été analysés des tissues testiculaires d'hommes avec azoospermie et SCO ainsi que ceux d'hommes avec spermatogenèse normale. Les miRNAs ont été isolés avec la trousse de Purification miRCURY'T RNA. Le système miRCURY LNA ${ }^{\text {TM }}$ Universal RT a été utilisé pour la détection quantitative de miARNs par PCR en temps réel. La localisation des miARNs a été réalisée par hybridation in situ (HIS) sur des tissus fixés au formol et inclus en paraffine en utilisant la technologie miRCURY LNA ${ }^{\text {TM }}$ microRNA ISH. Les analyses statistiques ont été faites avec GenEx V5.0.

Résultats: L'expression des microARNs a été faite chez 13 hommes féconds et 5 hommes avec un diagnostic confirmé de SCO diffus. L'expression de miR-202-5p est réduite d'un facteur $17(\mathrm{P}<0.00001)$ dans le tissu des hommes SCO par rapport au tissu des hommes à spermatogenèse normale. L'expression de miR-34c-5p est réduite d'un facteur $346(P<0.00001)$, celle de miR-10b d'un facteur $18(P<0.00001)$, celle de miR-191 d'un facteur 20 $(P=0.001)$ et celle de miR-126 d'un facteur $40(P<0.00001)$ dans les tissus des hommes SCO comparés à ceux des hommes à spermatogenèse normale. MiR-202-5p a été localisé par HIS dans les cellules de Sertoli des hommes à spermatogenèse normale, mais pas dans les cellules de Sertoli des hommes SCO.

Conclusions: Nombre de miARNs sont exprimés différentiellement chez les hommes féconds par rapport aux hommes SCO. MicroARN-202-5p est localisé dans les cellules de Sertoli et son expression diffère de façon marquée entre les hommes féconds et ceux dont les cellules germinales sont absentes; ceci suggère une nouvelle interaction entre les cellules somatiques et germinales constitutives de l'épithélium séminifère - impliquée dans la régulation de l'expression des microARNs.
\end{abstract}

Mots-clés: microARN, Spermatogenèse, Infécondité masculine, miR-202-5p, Cellules de Sertoli

\section{Background}

Infertility affects $10 \%-15 \%$ of couples worldwide (WHO, 1983) [1]. Half of all infertility cases are due to male factors, and about $60-75 \%$ of male infertility is idiopathic. Most "idiopathic" male infertility is thought to be caused by yet-to-be-identified genetic defects [2]. Spermatogenesis is a multistep complex process that displays strictly a regulated spatiotemporal gene expression, and during certain aspects of germ cell division, mRNA translation is significantly repressed [3]. Studies have indicated that microRNAs (miRNAs) may play a role in translational repression during spermatogenesis [4]. Therefore the deregulation of miRNAs could play an essential role in spermatogenic dysfunction.

miRNAs are 20 to 30 nucleotide noncoding single strand RNA molecules that act to regulate mRNA stability, and translation. They interact with their mRNA target through base-pairing, generally in their 3'UTR [5]. miRNAs appear to be evolutionarily conserved and play critical roles in a variety of biological processes in different cell types. Some miRNA show a tissue-specific expression, and several experiments have confirmed their importance in regulating cellular growth and differentiation $[5,6]$. Moreover, the overexpression of a tissue-specific miRNA in nonrelated cells shifts its transcriptome toward that of the lineage expressing the miRNA, making them a possible target for therapeutic use [7].
The majority of published literature on miRNAs focuses on the role they play in biological processes, including cell proliferation, differentiation, cell growth, death, and resistance to stress $[8,9]$. Differences in expression profiles of miRNAs have been linked to cancer, heart disease and male infertility [10-13]. However, despite intensive investigations, the cell type specificity of miRNA expression remains poorly understood. In this study we quantitatively examined miRNAs expression in normal human testis and in men with a severe form of infertility: azoospermia associated with Sertoli Cell Only (SCO) syndrome. We also localized miRNAs of interest in testicular tissue to guide a greater understanding of their potential role in spermatogenesis.

\section{Methods}

\section{Testicular tissues}

Weill Cornell Medical College Institutional review board approval was obtained for this study. Testicular tissue for SCO were obtained from male infertility patients during therapeutically necessary procedures and were snap frozen at the time of procurement, or sent to create formalinfixed paraffin-embedded (FFPE) sections. These men were azoospermic, had Sertoli cell-only documented on testis biopsy, and they had SCO documented in all dissected regions of the testis using a microsurgical approach for testis evaluation as part of a therapeutic attempt at sperm 
retrieval. Normal testicular tissue was obtained from men with obstructive azoospermia as well as from testes of organ donors utilizing an approved procurement protocol. Written informed consent was obtained from the patient for the publication of this report and any accompanying images.

\section{RNA isolation}

Total RNA was isolated from testicular tissue using the miRCURY ${ }^{\mathrm{mi}}$ RNA Isolation Kit (Cat No. 300111, Exiqon Inc. Vedbaek, Denmark). It is based on spin column chromatography using a proprietary resin as the separation matrix. This method of purification of total RNA allows for the isolation of the very small $(<200$ nucleotide) RNA fraction.

In brief, the frozen tissue is completely homogenized in a lysis solution using TissueRuptor. The lysate is incubated with Proteinase $\mathrm{K}$ for protein removal and loaded on a spin column. The removal of genomic DNA is performed directly on the column with DNase I (Qiagen, Venlo, Limburg) at a final concentration of $0.25 \mathrm{Kunitz}$ unit/ $\mu \mathrm{L}$. Eluted total RNA was either used for cDNA synthesis or stored in $-80^{\circ}$ Celsius. RNA concentration was measured with a fluorescence based quantitation assay using $\mathrm{Qbit}^{\circ}$ fluorometer (Life Technology ${ }^{\text {mix }}$, NY, USA), and the integrity of RNA was evaluated by calculating RNA integrity number (RIN, based on the detection of $18 \mathrm{~S}$ and $28 \mathrm{~S}$ and the amount of degradation products) on Agilent Bioanalyzer 2100 (Aligent Technologies, CA, USA). Only RNAs with RIN greater to or equal to 7 were used in the expression studies, this indicate that the RNA sample has minimal degradation products.

\section{Design of custom Pick-\&-Mix testis specific miRNAs panels}

Nineteen miRNAs that had been previously reported to be highly expressed in the testis were chosen to design a custom made Pick and Mix testis specific miRNA human panel [14]. Additionally, 3 miRNAs (miR-103, miR191 and miR-423-5p) with stable expression in human testis tissue were included to serve as reference miRNAs in the expression analysis. Each plate is designed to accept $22 \times 4$ samples in a pre-defined 96-well panel format to screen 4 different RNAs in one setting. Two wells for each sample were used for inter-plate calibrator (annotated as UniSp3 IPC) to aid with performing plateto-plate and run-to-run normalization analysis. The miRNAs panels were ordered and prepared from Exiqon Inc. (Vedbaek, Denmark). miRNA names, target sequences and their catalog numbers are listed in (Table 1).

\section{CDNA synthesis and real-time qPCR}

First strand of cDNA was synthesized using a Universal cDNA Synthesis Kit II (Exiqon, Cat. No 203301). An
Table 1 miRNA's names, target sequences and catalog numbers

\begin{tabular}{lll}
\hline Human miRNA & Target sequence & Product Cat. No \\
\hline hsa-miR-10b-3p & ACAGAUUCGAUUCUAGGGGAA & 204514 \\
hsa-miR-10b & UACCCUGUAGAACCGAUUUGUG & 204753 \\
hsa-miR-34c-3p & AAUCACUAACCACACGGCCAGG & 204373 \\
hsa-miR-34c-5p & AGGCAGUGUAGUUAGCUGAUUGC & 204407 \\
hsa-miR-99b-3p & CAAGCUCGUGUCUGUGGGUCCG & 204064 \\
hsa-miR-99b & CACCCGUAGAACCGACCUUGCG & 204367 \\
hsa-miR-125a-3p & ACAGGUGAGGUUCUUGGGAGCC & 204446 \\
hsa-miR-125a-5p & UCCCUGAGACCCUUUAACCUGUGA & 204339 \\
hsa-miR-126-5p & CAUUAUUACUUUUGGUACGCG & 204584 \\
hsa-miR-126 & UCGUACCGUGAGUAAUAAUGCG & 204227 \\
hsa-miR-202-5p & UUCCUAUGCAUAUACUUCUUUG & 204730 \\
hsa-miR-202 & AGAGGUAUAGGGCAUGGGAA & 204101 \\
hsa-miR-204 & UUCCCUUUGUCAUCCUAUGCCU & 204507 \\
hsa-miR-506 & UAAGGCACCCUUCUGAGUAGA & 204539 \\
hsa-miR-508-3p & UGAUUGUAGCCUUUUGGAGUAGA & 204480 \\
hsa-miR-508-5p & UACUCCAGAGGGCGUCACUCAUG & 204077 \\
hsa-miR-509-3p & UGAUUGGUACGUCUGUGGGUAG & 204458 \\
hsa-miR-509-3-5p & UACUGCAGACGUGGCAAUCAUG & 204503 \\
hsa-miR-514 & AUUGACACUUCUGUGAGUAGA & 204645 \\
hsa-miR-103 & AGCAGCAUUGUACAGGGCUAUGA & 204063 \\
hsa-miR-191 & CAACGGAAUCCCAAAAGCAGCUG & 204306 \\
hsa-miR-423-5p & UGAGGGGCAGAGAGCGAGACUUU & 204593 \\
\hline & & \\
\hline
\end{tabular}

artificial RNA (kit based RNA spike-in) was added to each reverse transcription reaction as a control to confirm that the reverse transcription and amplification occurred with equal efficiency in all samples. Twenty nanogram of total RNA in $4 \mu \mathrm{L}$ volume was mixed with $16 \mu \mathrm{L}$ reverse transcriptase (RT) master mix containing reaction buffer. Enzyme mix and spike-in were incubated in a thermocycler at $42^{\circ}$ Celsius for $60 \mathrm{~min}$. RT was then heat-inactivated at $95^{\circ}$ Celsius for $5 \mathrm{~min}$ and the reactions were cooled down and stored in $-20^{\circ}$ Celsius. Negative controls excluding template from the reverse transcription reaction were included and profiled as for the test samples.

The levels of miRNAs in whole testis samples was measured using real-time PCR with custom Pick-andMix testis-specific panels and $\mathrm{SYBR}^{\circ}$ Green master mix from Exiqon, (Cat No. 203450). Each plate was preloaded with dried out miRNAs in all wells, cDNA from each patient was diluted 1:100 and combined with $2 \times$ SYBR $^{\circ}$ Green master (1:1). Samples and controls were adjusted to $10 \mu \mathrm{L}$ volume in all 24 wells. The amplification reactions were performed on a LightCycler 480 Roche platform (Roche, IN, USA). The samples were subjected to $95^{\circ}$ Celsius denaturation for $10 \mathrm{~min}$ 
followed by 45 cycles of $95^{\circ}$ Celsius for $10 \mathrm{sec}$ and $60^{\circ}$ Celsius for $1 \mathrm{~min}$ with optical read at the end of every cycle. Melting curve analysis was carried out to check for examination of amplification products.

\section{In Situ Hybridization (ISH)}

To localize the differentially expressed miRNAs from testicular tissues (to determine the cellular origin and evaluate relative expression levels) ISH was performed on FFPE sections. Double-Dig-labeled probe for miR202-5p (miRCURY LNA ${ }^{\text {su }}$ Detection probe, $5^{\prime}$-DIG and 3'-DIG labeled hsa-miR-202-5p, Exiqon, Cat No. 38814-15) was used. As a negative control, a scramble probe was used (Probe No. 90-001). Additionally, as positive control for testicular tissue, the has-miR-126 probe for endothelial cells was tested (Probe No. 90008). ISH was performed using manufacturers instructions. In brief, all FFPE sections were deparaffinized in two washes of CitriSolve for 15 min and then hydrated through sequentially increasing ethanol solutions. The target demasking step was carried out in Proteinase $\mathrm{K}$ solution at a concentration of $15 \mu \mathrm{g} / \mathrm{mL}$ at $37^{\circ}$ Celsius for $10 \mathrm{~min}$. Following pre-digestion that allows the access of double-DIG-labeled LNA ${ }^{\mathrm{m}}$ probes to hybridize to the miRNA sequence, sections were dehydrated in gradual ethanol solutions and dried completely for $20 \mathrm{~min}$. Probe, denatured at $90^{\circ}$ Celsius for $4 \mathrm{~min}$, was diluted in $1 \mathrm{x}$ hybridization solution to a final concentration of $40 \mathrm{nM}$. A total of $50 \mu \mathrm{L}$ was applied on each slide. The slides were then covered with cover glass, sealed with Fixogum and hybridized for $60 \mathrm{~min}$. To optimize performance for each probe and to ensure optimal signal to noise ratio, hybridization was performed at a temperature of $30^{\circ}$ Celsius below the probe melting temperature. The slides were passed through stringent washing steps of $5 \mathrm{X}, 1 \mathrm{X}$ and $0.2 \mathrm{X}$ SSC at hybridization temperature. Digoxin was recognized by a sheep antiDIG-AP directly conjugated with the enzyme Alkaline Phosphatase (AP) (Roche, Cat. No. 11093274 910). The specimens were incubated for $60 \mathrm{~min}$ at room temperature. AP converted the applied substrate NBT/ BCIP (Roche, Cat. No. 11697471 001) to the soluble substrates 4-Nitro-Blue Tetrazolium (NBT) and 5-Bromo4-Chloro-3'-Indolylphosphate (BCIP) into a water and alcohol insoluble dark-blue NBT-BCIP precipitate that appears on slides after $2 \mathrm{~h}$ of incubation at $30^{\circ}$ Celsius in the dark. The reaction was stopped and slides were counterstained with filtered Nuclear Fast Red ${ }^{\mathrm{mm}}$ (Vector laboratories, Cat. No. H-3403). After washing in tap water for $10 \mathrm{~min}$ and dehydration with ethanol, the slides were mounted using Eukitt ${ }^{\circ}$ mounting media (VWR, Cat. No. 361894G). The slides were examined by light microscopy the subsequent day and images were obtained using Kodak microscope.

\section{Statistical analysis Analysis of miRNA}

The expression level of miRNAs was performed based on absolute quantification analysis using second derivative method by LightCycler 480 software from Roche allowing $\mathrm{Cp}$ values to be calculated. GenEX software (MultiD Analyses AB, Göteborg, Sweden) was used to analyze and normalize the miRNA-qPCR data. This program allows the correction of PCR efficiencies, the compensation for differences between runs by normalizing with interplate calibrators, and normalization with endogenous reference genes. Data was normalized to PCR efficiency (E), $C p E=100 \%=C p E \frac{\log (1+E)}{\log 2}$, and for differences between runs using Interplate normalisation and Interplate control (IPC): Cpnormal $=C p-\frac{1}{n} \sum_{i=1}^{n} C p I C$. The $\mathrm{Cp}$ values of genes of interest were normalized to plate average after removing $\mathrm{Cp}$ values that were greater than 38. Normalisation of the gene of interest (GOI) to reference $\mathrm{Cp}$ was done using the following formula: $C p G O I$, norm $=C p G O I-\frac{1}{n} \sum_{i=1}^{n}$ Cpavg. SCO was further normalized to the relative expression of the same miRNA in normal tissue to determine the fold changes of differential expression in SCO tissue. The formula for normalisation of $\mathrm{SCO}$ to normal tissues was the RatioT $/ N=2^{-C P(S C O)+C p(\text { Normal })}$. The normality distribution of the data was tested by the Kolmogorov-Smirnov test. Parametric analysis ( $t$-test according to Student with paired and unpaired values) was used as appropriate. Pvalues below 0.05 were regarded as statistically significant.

\section{Results}

Expression of miRNA was determined for 13 normal fertile men and 5 men with the confirmed diagnosis of diffuse SCO using the 96 well plates of previously selected primers that are relevant for testicular tissue. Mean age of the cohort was $35(\mathrm{SD} \pm 6.7)$ years old. By applying an unpaired two-tailed $t$-test for miRNAs that showed $>2$-fold change in the considered groups, we found 8out of the 22 miRNA with significant differences in expression levels when comparing the samples from SCO samples with the normal testicular samples $(\mathrm{P}<.005)$. Detail of miRNA expression for SCO samples compared to normal are listed in (Table 2). This is consistent with the fact that the greatest changes detected in SCO/Normal miRNA comparisons were for miR-34c-5p that was downregulated by a factor of 346 ( $\mathrm{P}<0.00001)$. mir-34c-5p is believed to be predominantly expressed in germ cells [10], reflecting the SCO miRNA expression pattern in our samples. miR-126 was downregulated by a factor of $40(\mathrm{P}<0.00001)$, miR-126-5p by a factor of 20.7 , miR-191 by a factor of $20(\mathrm{P}=0.001)$ in 
Table 2 miRNA expression profiling in normal vs. SCO

\begin{tabular}{|c|c|c|}
\hline miRNA & Normal vs. SCO & P-Value \\
\hline hsa-miR-34c-5p & -346 & $<0.00001$ \\
\hline hsa-miR-126 & -40 & $<0.00001$ \\
\hline hsa-miR-191 & -20 & $<0.001$ \\
\hline hsa-miR-126-5p & -20.7 & $<0.001$ \\
\hline hsa-miR-10b & -18 & $<0.0001$ \\
\hline hsa-miR-202-5p & -17 & $<0.00001$ \\
\hline hsa-miR-103 & -7 & 0.001 \\
\hline hsa-miR-514 & -5.8 & 0.01 \\
\hline hsa-miR-509-3-5p & -4.2 & 0.007 \\
\hline hsa-miR-204 & -4.2 & $<0.001$ \\
\hline hsa-miR-10b-3p & -3.3 & 0.06 \\
\hline hsa-miR-508-3p & -3 & 0.04 \\
\hline hsa-miR-125a-5p & -2 & 0.02 \\
\hline hsa-miR-99b-3p & -2.4 & 0.008 \\
\hline hsa-miR-99b & -2 & 0.008 \\
\hline hsa-miR-34c-3p & -2.3 & 0.06 \\
\hline hsa-miR-508-5p & -2 & 0.13 \\
\hline hsa-miR-506 & -2 & 0.14 \\
\hline hsa-miR-125a-3p & -1 & 0.40 \\
\hline hsa-miR-509-3p & 1 & 0.45 \\
\hline UniSp6 CP & 1 & 0.34 \\
\hline hsa-miR-423-5p & 1.5 & 0.11 \\
\hline hsa-miR-202 & 1.6 & 0.10 \\
\hline
\end{tabular}

SCO samples relative to normal testicular tissue. miR-202$5 p$ expression was reduced by 17 -fold $(\mathrm{P}<0.00001)$ in SCO men compared to normal. No significant increase in miRNA expression levels was seen in men with SCO relative to normal testicular tissue levels.

To further decipher the expression profile in testicular tissue, and to determine the cell types that express miR-202-5p, ISH was performed on both normal and $\mathrm{SCO}$ testicular tissue. Hybridization signal specific for of miR-202-5p was specifically detected in the Sertoli cells of men with normal spermatogenesis (Figures 1, 2 and 3). The tissue of men with confirmed SCO had no signal detectable for miR202-5p in Sertoli cells (Figures 4 and 5). These observations reflect that miR202-5p are selectively expressed in Sertoli cells in men with normal germ cells, but not in the Sertoli cells of men with SCO. This localization pattern of miR-202-5P is consistent with our qPCR results. There were no differences in expression of control miRNAs between men with normal spermatogenesis and SCO, using scramble for negative control and miR-126 specific to endothelial as a positive control.

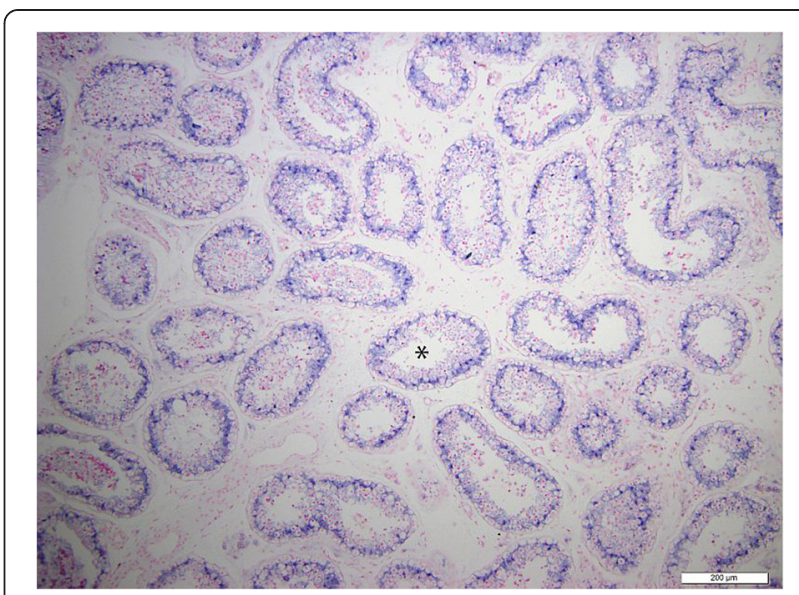

Figure 1 ISH of miR-202-5p, blue precipitate indicate cellular expression of miRNA in normal testicular tissue, ${ }^{*}$ normal seminiferous tubules, scale $200 \mu \mathrm{m}$.

\section{Discussion}

Profiling of miRNA in human and murine testis has previously been reported in multiple published studies [14-16]. The testis specific expression of miRNAs in normal men and men with clinical infertility have been corroborated by these studies as well as the data in this manuscript. Several miRNA clusters and their target genes as well as their chromosomal origin have also been examined [14,15]. However, the cellular localization of specific testicular miRNAs have not been well elucidated in human testicular tissue. Since azoospermic men with failed spermatogenesis have pathology ranging from Sertoli cell-only pattern to maturation arrest, or hypospermatogenesis, analysis of the cellular origins of these differentially expressed miRNAs is important to better reflect their potential regulatory roles in spermatogenesis and male infertility. In our study we

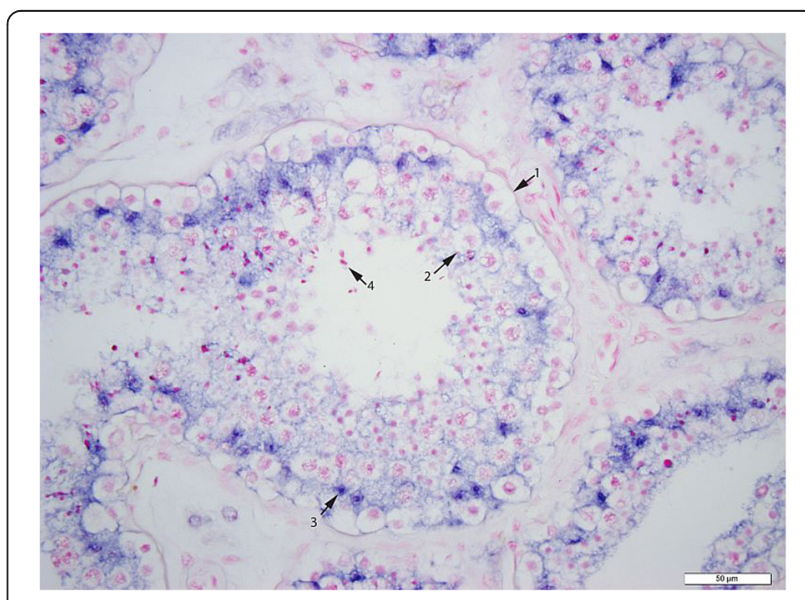

Figure 2 ISH of miR-202-5p, blue precipitate indicate cellular expression of miRNA in normal testicular tissue, 1 spermatogonia, 2 primary spermatocyte, 3 Sertoli cell, 4 spermatid, scale $50 \mu \mathrm{m}$. 


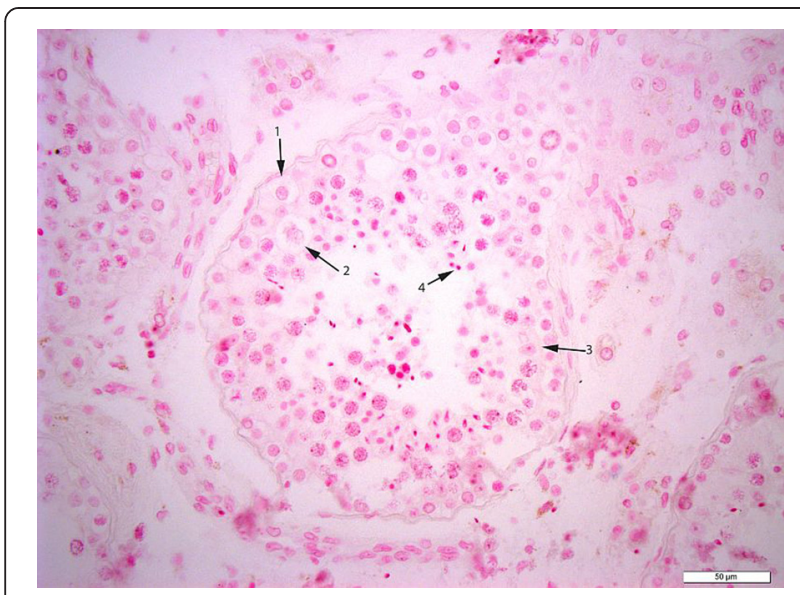

Figure 3 ISH of negative control in normal testicular tissue, 1 spermatogonia, 2 primary spermatocyte, 3 Sertoli cell, 4 spermatid, scale $50 \mu \mathrm{m}$.

used ISH to localize miRNA expression. ISH has been previously shown to reveal cellular localization of mRNAs and non-coding RNA [17].

Several of the testicular specific miRNAs identified in our study have been evaluated by previous studies. However, we identified eight novel miRNAs that have not been detected previously and may play a role in testicular function and spermatogenesis. We found that miR-204, miR-99b3p, miR-191, miR-509-3-5p, miR-99b, miR-10b, miR-126, miR-126-5p, miR-103 are downregulated in samples from men with SCO pathology pattern. We could only identify three prior reports on the use of ISH to localize miRNA to specific cell types in testes. ISH of the miR-34 family indicated that $\mathrm{miR}-34 \mathrm{~b} / \mathrm{c}$ are primarily localized to spermatocytes and spermatids in murine testicular tissue [15]. Whereas miR-34a appeared to be restricted to murine spermatogonia residing on the basal membrane of

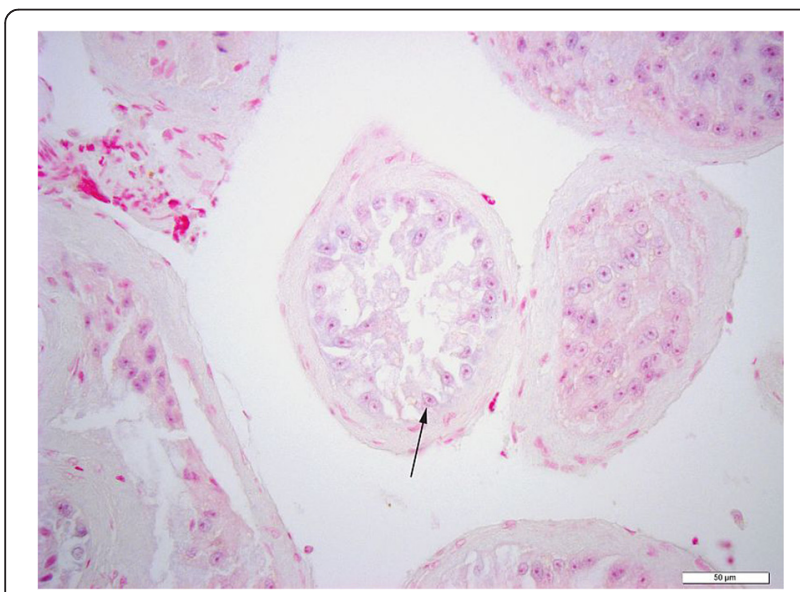

Figure 4 ISH miR-202-5p in testicular tissue of men with SCO, arrow Sertoli cells, scale $50 \mu \mathrm{m}$.

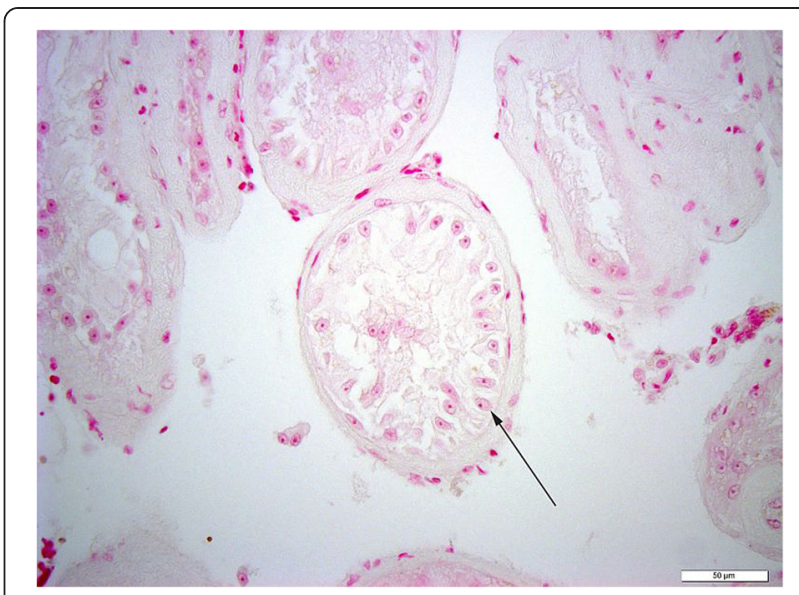

Figure 5 ISH negative control in testicular tissue of men with SCO, arrow Sertoli cells, scale $50 \mu \mathrm{m}$.

seminiferous tubules [18]. In another study, miR-383 was highly expressed in primary spermatocyte and poorly expressed in spermatids of samples of men with normal spermatogenesis; whereas the expression of miR-383 in tissues from men with severely impaired sperm production was noticeably lower compared with the control group [13]. Our study demonstrates that miR-202-5p is selectively expressed in Sertoli cells in men with normal germ cells, but not in the Sertoli cells of men with SCO.

To date, no direct physiological function for miR-202$5 p$ has been identified in humans. miR-202-5p/3p are a member of the let- 7 family. let- 7 was the first human miRNA to be discovered. let-7 and its family members are highly conserved across species in sequence and function. Deregulation of let-7 leads to a less differentiated cellular state and the development of cell-based diseases. In general high levels of let-7 expression is associated with cell differentiation and maturation [19]. miR-202-5p is expressed in Sertoli cells in the early XY gonad [20]. Its expression was found to be downstream of the testis-determining factor SOX9, that plays an important role in testicular development and maturation [21]. Previous studies have suggested that miR-202 expression increases in testicular tissue postnatally and during development, suggesting that the expression of miR-202-5p is up-regulated in the testis at later developmental stages [14]. These data indicate that miR-202-5p expression is associated with male gonad development, and its expression is restricted to Sertoli cells in the adult testis.

The pathophysiology that leads to SCO pathology pattern is not completely understood. It is debatable if Sertoli cells did not develop normally so that germ cells could not survive, or the function of Sertoli cells is normal, but SCO has arisen because of an inherent problem with the germ cells. Sertoli cell dysfunction secondary to 
the absence of other testicular cell types can occur [22,23]. The absence of germ cells can result in de-differentiation of Sertoli cells, so that Sertoli cell function reflects that of immature Sertoli cells, leading to loss of expression of miR-202-5p expression. Conversely, it is important to recognize that the absence of germ cells may also be a reflection of underlying abnormalities in the Sertoli cells and failure of their maturation [24]. During puberty, Sertoli cells undergo a radical change in their morphology and function, reflecting maturation from an immature proliferative state to a non-proliferative state [25]. This maturation process is highly dependent on miRNAs, studies have shown that Dicer-mutant Sertoli cells show a progressively aberrant development and loss of function [26]. The Sertoli cell maturation process switches on multiple cell functions. Previous studies have suggested that miR202 expression increases in testicular tissue postnatally and during development, indicating that the expression of miR-202-5p is up regulated in the testis at later stages during development [14]. Further rodent studies may help elucidate whether loss of miR-202-5p is the cause or a consequence of loss of germ cells in men with Sertoli Cell Only syndrome.

\section{Conclusion}

Our results reveal several miRNAs that are differentially expressed in normal fertile men compared to men with SCO. miR-202-5p is highly expressed in Sertoli cells when germ cells are present. This germ cell-dependent expression of miR-202-5p suggests a functional role of this miRNA in Sertoli cell maturation and/or regulation of spermatogenesis.

\section{Abbreviation \\ SCO: Sertoli Cell Only; ISH: In Situ Hybridizations; FFPE: Formalin-Fixed Paraffin Embedded; miRNAs: microRNAs; ISH: In Situ Hybridization.}

\section{Competing interests}

The authors declare that they have no competing interests.

\section{Authors' contributions}

AAD participated in the design of the study, carried out the ISH, microRNA profiling, preformed the statistical analysis, drafted the manuscript and approved the manuscript. AM carried out the ISH, preformed the microRNA profiling, drafted and approved the manuscript. MSW carried out stasistical analysis, and drafted and approved the manuscript. BR carried out pathological analysis, and help draft the manuscript. DAP participated in the design of the study, carried out the ISH, microRNA profiling, preformed the statistical analysis, drafted the manuscript and approved the manuscript. PS participated in the design of the study, preformed the statistical analysis, drafted the manuscript and approved the manuscript. All authors read and approved the final manuscript.

\section{Funding}

"Research reported in this publication was supported by the Eunice Kennedy Shriver National Institute of Child Health \& Human Development of the National Institutes of Health under Award Number U54HD076210. The content is solely the responsibility of the authors and does not necessarily represent the official views of the National Institutes of Health."

\section{Author details}

${ }^{1}$ Department of Reproductive Medicine, Weill Cornell Medical College, 525 East 68th St Starr 900, New York, NY 10065, USA. ${ }^{2}$ Department of Pathology, Weill Cornell Medical College, 522 East 68th St. Starr 100, New York, NY 10065, USA.

Received: 15 November 2014 Accepted: 12 January 2015

Published online: 03 March 2015

\section{References}

1. World Health Organization. Report of the meeting on the prevention of infertility at the primary health care level. 1984.

2. Okada H, Tajima A, Shichiri K, Tanaka A, Tanaka K, Inoue I. Genome-wide expression of azoospermia testes demonstrates a specific profile and implicates ART3 in genetic susceptibility. PLoS Genet. 2008;4(2):e26. doi:10.1371/journal.pgen.0040026.

3. Eddy EM, O'Brien DA. Gene expression during mammalian meiosis. Curr Top Dev Biol. 1998;37:141-200.

4. Hayashi K, Chuva de Sousa Lopes SM, Kaneda M, Tang F, Hajkova P, Lao K, et al. MicroRNA biogenesis is required for mouse primordial germ cell development and spermatogenesis. PLoS One. 2008;3(3):e1738. doi:10.1371/journal.pone.0001738.

5. Bartel DP. MicroRNAs: target recognition and regulatory functions. Cell. 2009;136(2):215-33. doi:10.1016/j.cell.2009.01.002.

6. Kloosterman WP, Plasterk RH. The diverse functions of microRNAs in animal development and disease. Dev Cell. 2006;11(4):441-50. doi:10.1016/j.devcel.2006.09.009.

7. Lim LP, Lau NC, Garrett-Engele P, Grimson A, Schelter JM, Castle J, et al. Microarray analysis shows that some microRNAs downregulate large numbers of target mRNAs. Nature. 2005;433(7027):769-73. doi:10.1038/nature03315.

8. Ambros V. The functions of animal microRNAs. Nature. 2004;431(7006):350-5. doi:10.1038/nature02871.

9. Bartel DP. MicroRNAs: genomics, biogenesis, mechanism, and function. Cell. 2004;116(2):281-97.

10. Abu-Halima M, Backes C, Leidinger P, Keller A, Lubbad AM, Hammadeh M, et al. MicroRNA expression profiles in human testicular tissues of infertile men with different histopathologic patterns. Fertil Steril. 2014;101(1):78-86 e2. doi:10.1016/j.fertnstert.2013.09.009.

11. Esquela-Kerscher A, Slack FJ. Oncomirs - microRNAs with a role in cancer. Nat Rev Cancer. 2006;6(4):259-69. doi:10.1038/nrc1840.

12. van Rooij E, Olson EN. MicroRNAs: powerful new regulators of heart disease and provocative therapeutic targets. J Clin Invest. 2007;117(9):2369-76. doi:10.1172/JCl33099.

13. Lian J, Zhang $X$, Tian $H$, Liang N, Wang $Y$, Liang $C$, et al. Altered microRNA expression in patients with non-obstructive azoospermia. Reprod Biol Endocrinol. 2009;7:13. doi:10.1186/1477-7827-7-13.

14. Ro S, Park C, Sanders KM, McCarrey JR, Yan W. Cloning and expression profiling of testis-expressed microRNAs. Dev Biol. 2007;311(2):592-602. doi:10.1016/j.ydbio.2007.09.009.

15. Bouhallier F, Allioli N, Lavial F, Chalmel F, Perrard MH, Durand P, et al. Role of miR-34c microRNA in the late steps of spermatogenesis. RNA. 2010;16(4):720-31. doi:10.1261/rna.1963810.

16. Abu-Halima M, Hammadeh M, Schmitt J, Leidinger P, Keller A, Meese E, et al. Altered microRNA expression profiles of human spermatozoa in patients with different spermatogenic impairments. Fertil Steril. 2013;99(5):1249-55 e16. doi:10.1016/j.fertnstert.2012.11.054.

17. Mitchell BS, Dhami D, Schumacher U. In situ hybridisation: a review of methodologies and applications in the biomedical sciences. Med Lab Sci. 1992:49(2):107-18.

18. Bao J, Li D, Wang L, Wu J, Hu Y, Wang Z, et al. MicroRNA-449 and microRNA-34b/c function redundantly in murine testes by targeting E2F transcription factor-retinoblastoma protein (E2F-pRb) pathway. J Biol Chem. 2012;287(26):21686-98. doi:10.1074/jbc.M111.328054.

19. Roush S, Slack FJ. The let-7 family of microRNAs. Trends Cell Biol. 2008;18 (10):505-16. doi:10.1016/j.tcb.2008.07.007.

20. Rakoczy J, Fernandez-Valverde SL, Glazov EA, Wainwright EN, Sato T, Takada S, et al. MicroRNAs-140-5p/140-3p modulate Leydig cell numbers in the developing mouse testis. Biol Reprod. 2013;88(6):143. doi:10.1095/biolreprod.113.107607. 
21. Wainwright EN, Jorgensen JS, Kim Y, Truong V, Bagheri-Fam S, Davidson T, et al. SOX9 regulates microRNA miR-202-5p/3p expression during mouse testis differentiation. Biol Reprod. 2013;89(2):34. doi:10.1095/biolreprod.113.110155.

22. Boujrad N, Hochereau-de Reviers MT, Carreau S. Evidence for germ cell control of Sertoli cell function in three models of germ cell depletion in adult rat. Biol Reprod. 1995;53(6):1345-52.

23. Guitton N, Touzalin AM, Sharpe RM, Cheng CY, Pinon-Lataillade G, Meritte $H$, et al. Regulatory influence of germ cells on sertoli cell function in the pre-pubertal rat after acute irradiation of the testis. Int J Androl. 2000;23(6):332-9.

24. Bar-Shira Maymon B, Paz G, Elliott DJ, Hammel I, Kleiman SE, Yogev L, et al. Maturation phenotype of Sertoli cells in testicular biopsies of azoospermic men. Hum Reprod. 2000;15(7):1537-42.

25. Tan KA, Turner KJ, Saunders PT, Verhoeven G, De Gendt K, Atanassova N, et al. Androgen regulation of stage-dependent cyclin D2 expression in Sertoli cells suggests a role in modulating androgen action on spermatogenesis. Biol Reprod. 2005;72(5):1151-60. doi:10.1095/biolreprod.104.037689.

26. Kim GJ, Georg I, Scherthan H, Merkenschlager M, Guillou F, Scherer G, et al. Dicer is required for Sertoli cell function and survival. Int J Dev Biol. 2010;54 (5):867-75. doi:10.1387/ijdb.092874gk.

\section{Submit your next manuscript to BioMed Central and take full advantage of:}

- Convenient online submission

- Thorough peer review

- No space constraints or color figure charges

- Immediate publication on acceptance

- Inclusion in PubMed, CAS, Scopus and Google Scholar

- Research which is freely available for redistribution 